\title{
Synthesis of Illisimonin a Skeleton by Intramolecular Diels-Alder Reaction of Ortho-Benzoquinones and Biomimetic Skeletal Rearrangement of Allo-Cedranes
}

\author{
Takahiro Suzuki ${ }^{1, *} \mathbb{\infty}$, Riko Nagahama ${ }^{2}$, Muhammad Aiman Fariz ${ }^{1}$, Yuki Yukutake ${ }^{2}$, Kazutada Ikeuchi ${ }^{1} \mathbb{C}$ \\ and Keiji Tanino ${ }^{1}$ \\ 1 Department of Chemistry, Hokkaido University, Sapporo 060-0810, Hokkaido, Japan; \\ aimanfab@gmail.com (M.A.F.); ikeuchi@sci.hokudai.ac.jp (K.I.); ktanino@sci.hokudai.ac.jp (K.T.) \\ 2 Graduate School of Chemical Sciences and Engineering, Hokkaido University, \\ Sapporo 060-0810, Hokkaido, Japan; riko-nagahama@ds-pharma.co.jp (R.N.); \\ yuki-yukutake@eis.hokudai.ac.jp (Y.Y.) \\ * Correspondence: takahiro-suzuki@sci.hokudai.ac.jp
}

check for updates

Citation: Suzuki, T.; Nagahama, R.; Fariz, M.A.; Yukutake, Y.; Ikeuchi, K.; Tanino, K. Synthesis of Illisimonin a Skeleton by Intramolecular Diels-Alder Reaction of

Ortho-Benzoquinones and Biomimetic Skeletal Rearrangement of Allo-Cedranes. Organics 2021, 2 , 306-312. https://doi.org/10.3390/ org2030016

Academic Editor: Stéphane P. Roche

Received: 5 August 2021

Accepted: 25 August 2021

Published: 2 September 2021

Publisher's Note: MDPI stays neutral with regard to jurisdictional claims in published maps and institutional affiliations.

Copyright: (c) 2021 by the authors. Licensee MDPI, Basel, Switzerland. This article is an open access article distributed under the terms and conditions of the Creative Commons Attribution (CC BY) license (https:// creativecommons.org/licenses/by/ $4.0 /)$.

\begin{abstract}
Illisimonin A is a new sesquiterpene isolated from Illicium simonsii, and it possesses a novel $5 / 5 / 5 / 5 / 5$ pentacyclic skeleton. The tricyclic skeleton of illisimonin A, tricyclo[5.2.1.0 $0^{1,5}$ ]decane, is presumed to be biosynthesized from allo-cedranes via a skeletal rearrangement. Herein, we report the concise synthesis of highly oxidized allo-cedranes by an intramolecular Diels-Alder reaction using ortho-benzoquinones and demonstrate the biomimetic transformation of allo-cedranes by a retro-Claisen/aldol pathway.
\end{abstract}

Keywords: biomimetic synthesis; Diels-Alder reaction; illicium sesquiterpene; natural product synthesis; skeletal rearrangement

\section{Introduction}

Illicium sesquiterpenes are a family of natural products, many of which show activities on the central nervous system, such as GABA receptors [1-3]. The structures of illicium sesquiterpenes, such as anisatin (1), jiadifenolide (2), tashironin (3), and merrilactone A (4), feature highly oxidized carbon frameworks containing consecutive tetra-substituted carbon centers (Figure 1). In the biosynthesis, allo-cedrane is a common ancestor of these sesquiterpenes by oxy-functionalization and $\mathrm{C}-\mathrm{C}$ bond cleavage/formation. The $\mathrm{C} 6-\mathrm{C} 11$ bond cleavage affords seco-prezizaanes (e.g., 1 and 2), while the C6-C7/C10-C11 cleavages and the $\mathrm{C} 6-\mathrm{C} 10$ bond formation produce anislactones (e.g., 4) [4-9]. Due to their biological activity and complex molecular structure, these compounds have attracted the interest of synthetic chemists. Numerous total syntheses and synthetic studies of these compounds have been reported, especially in the last decade [10-23]. Illisimonin A (5), isolated from Illicium simonsii in 2017, is a new sesquiterpene that has a neuroprotective effect on oxygen-glucose deprivation-induced cell injury [24]. Unlike the other illicium sesquiterpenes, 5 possesses a novel 5/5/5/5/5 pentacyclic skeleton, 6,12dioxapentacyclo[6.6.0.0 $\left.0^{1,5} \cdot 0^{5,10} \cdot 0^{9,13}\right]$ tetradecane, including three five-membered carbon rings, a five-membered lactone, and a five-membered lactol. Further, the carbon flamework of 5, tricyclo[5.2.1.0 $0^{1,5}$ ]decane, is unprecedented as a natural product and possesses seven consecutive asymmetric tetra-substituted carbons. The elegant total synthesis of 5 by Rychnovsky's group [25] has revised the absolute stereochemistry, as shown in Figure 1. Therefore, we postulated that the biosynthesis of 5 is mediated by the cleavage of the C6-C7 bond and the formation of the C6-C8 bond from the allo-cedrane skeleton. In this study, we investigated the biomimetic transformation from the highly oxidized allo-cedranes to the carbon framework of 5 . Herein, we report the concise synthesis of the highly 
oxidized allo-cedranes by an intramolecular Diels-Alder (IMDA) reaction using orthobenzoquinones. Further, we demonstrate the biomimetic transformation of allo-cedranes via a retro-Claisen/aldol pathway.

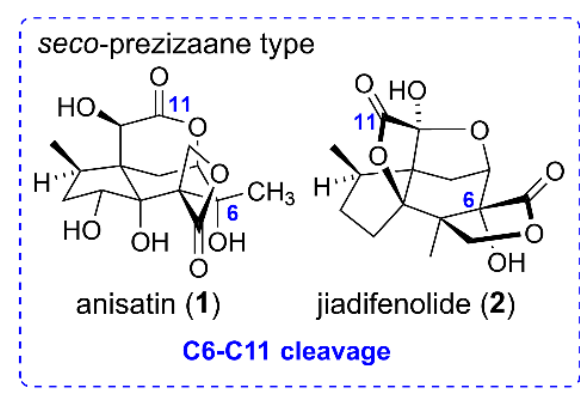

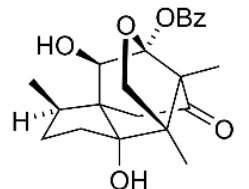

tashironin (3)

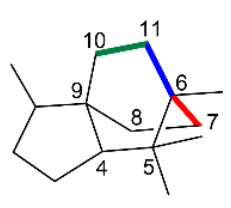

allo-cedrane

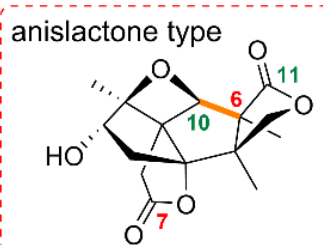

merrilactone A (4)

C6-C7 cleavage

C10-C11 cleavage C6-C10 formation

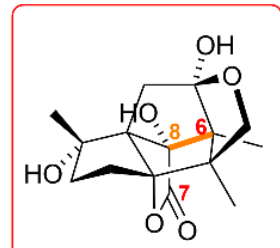

illisimonin A (5)

C6-C7 cleavage C6-C8 formation

Figure 1. Illisimonin A and its related compounds.

\section{Results and Discussion}

The synthetic route is shown in Scheme 1. We postulated that the following two pathways are possible for the skeletal rearrangement from allo-cedrane to the tricyclic core of 5: (i) a retro-Claisen condensation/aldol reaction and (ii) a benzilic acid rearrangement (BAR) [26]. The treatment of triketone 6a with an oxygen nucleophilic reagent led to the C6-C7 bond cleavage, thereby affording 7a. A subsequent addition reaction from the resulting enolate to $\mathrm{C} 8$ ketone led to the formation of a C6-C8 bond, affording a 5-5-5 tricyclic core (8a). Furthermore, the addition of an oxygen nucleophilic reagent to the C7 ketone of $\mathbf{6 b}$ produced a tricyclic core $(\mathbf{8 b})$ via the BAR pathway. However, the BAR of bicyclo[2.2.2] octan-1,2-dione is rare, with only one example reported by the Ghatak group in 1993 [27]. The biosynthesis may involve a retro-Claisen/aldol pathway; however, the BAR pathway is synthetically challenging. Therefore, we decided to investigate both synthetic pathways. Allo-cedrane derivatives $\mathbf{6 a}$ and $\mathbf{6 b}$ would be synthesized by the IMDA reaction of benzoquinone $\mathbf{1 0}$ via transition state 9 [28,29]. Benzoquinone $\mathbf{1 0}$ can be prepared by the addition reaction of Grignard reagent 12 to aldehyde 11, followed by the oxidation of the resulting o-methoxyphenol. Notably, there are few reported examples of the IMDA using ortho-benzoquinones and the BAR of bicyclo[2.2.2]octandiones; the characteristics of these reactions, especially stereoselectivities, are unpredictable.
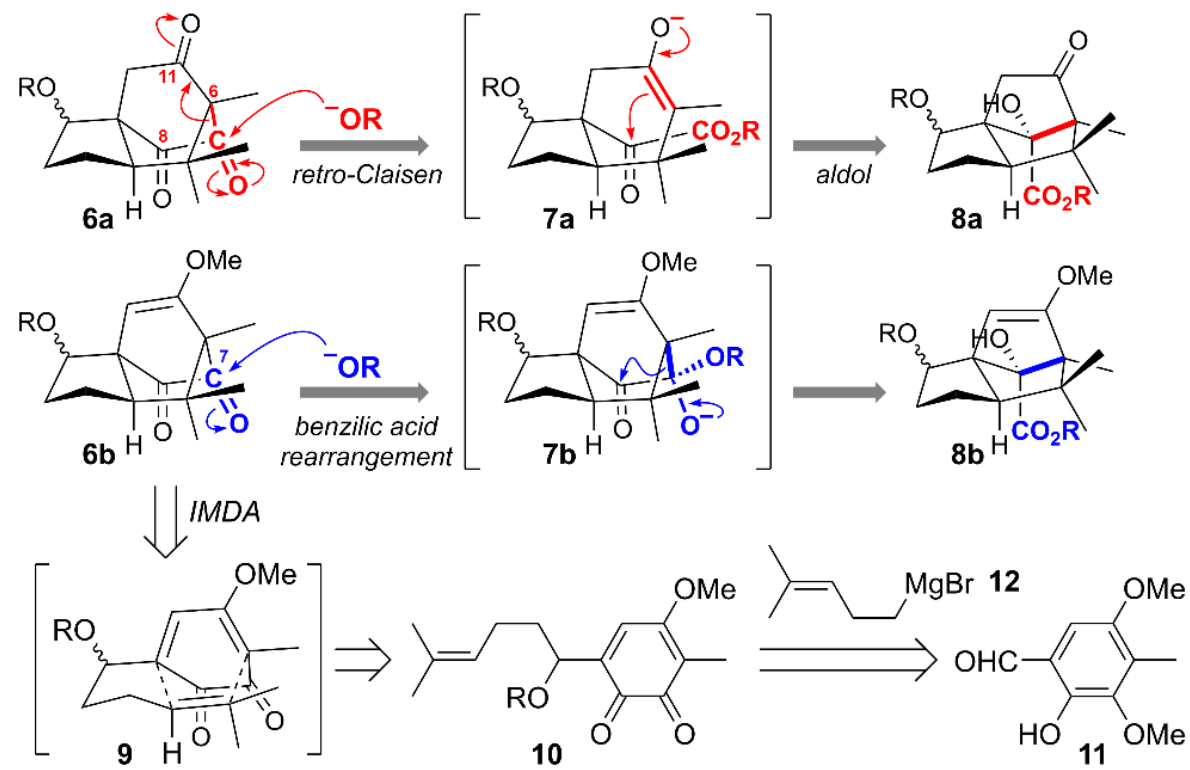

Scheme 1. Synthetic strategy toward the illisimonin A skeleton. 
The preparation of ortho-benzoquinones commenced with the $\mathrm{SnCl}_{4}$-mediated formylation of commercially available 13 and the following Dakin oxidation, according to the literature [30] (Scheme 2). The resulting phenol 14 was subjected to site-selective formylation with hexamethylenetetramine (HMTA) in trifluoroacetic acid (TFA)/trifluoroacetic anhydride (TFAA) to afford benzaldehyde 11 [31] in a 54\% yield. Further, the addition reaction of 12 to 11 afforded diol 15 in a 93\% yield. The selective protection of the hydroxyl group at the benzylic position was achieved using triisopropylsilyl trifluoromethanesulfonate (TIPSOTf) and $N, N$-diisopropylethylamine (DIPEA) to afford phenol $\mathbf{1 6}$ in an 84\% yield. Oxidative dearomatization using $o$-iodoxybenzoic acid (IBX) [32] and the hydrolysis of the resulting quinonium cation afforded ortho-benzoquinone 17 in a $67 \%$ yield.

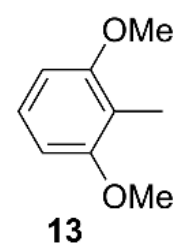<smiles>COc1cc(C(O)CCC=C(C)C)c(O)c(OC)c1C</smiles><smiles>COc1ccc(O)c(OC)c1C</smiles>

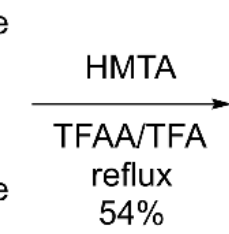<smiles>COc1cc(C=O)c(O)c(OC)c1C</smiles>

11
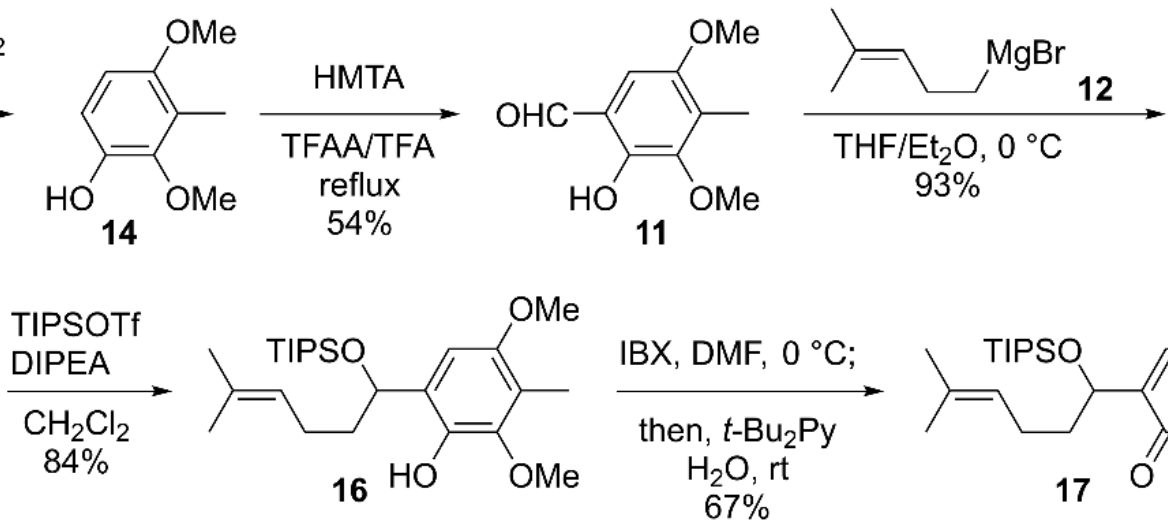

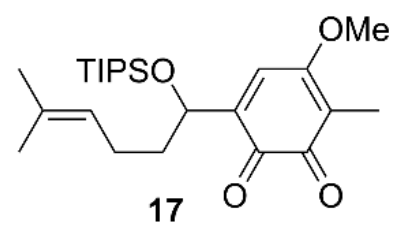

Scheme 2. Preparation of IMDA precursor 17.

Next, the IMDA reaction was pursued using 17 (Scheme 3). The reaction under thermal conditions produced two cycloadducts, 18 and 19, as an inseparable mixture. The removal of the TIPS group using tetra- $n$-butylammonium fluoride (TBAF) afforded a mixture of alcohols 20 and 21. The analytical amount of 20 derived from the major cycloadduct was isolated, and its X-ray crystallographic analysis revealed that the IMDA reaction favored the undesired facial selectivity (Figure 2 and Supplementary Materials). Notably, since compound 20 also possesses an allo-cedrane skeleton, our synthetic method can be applied to the synthesis of other illicium sesquiterpenes. The Dess-Martin oxidation of the mixture of $\mathbf{2 0}$ and $\mathbf{2 1}$ retained the diastereomeric ratio of 6:1 in a mixture of the resulting triketone. Thus, the minor cycloadduct 19 possessed the desired stereochemistry. Moreover, the whole stereochemistry of the minor cycloadduct 19 was clearly determined using the X-ray crystallographic analysis of compound 22 derived from 19 by degradation during BAR studies. Our initial expectation was that TS B, in which the bulky siloxy group was orthogonal to the quinone plane and the prenyl group was antiperiplanar to the ketone, would be favorable, and that 19 would be the preferred isomer (Figure 3). However, the IMDA reaction afforded isomer 18, which suggests that the reaction probably proceeded through TS A, where the prenyl group was orthogonal to the quinone plane, while the siloxy group and the ketone were antiperiplanar. 


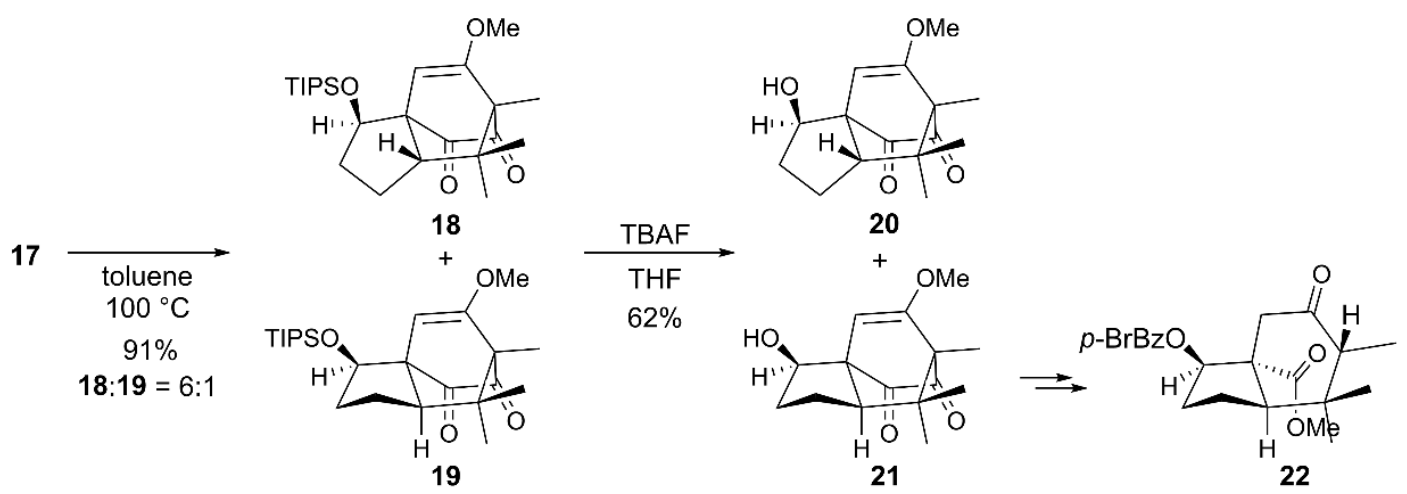

Scheme 3. IMDA reaction of ortho-benzoquinone 17.
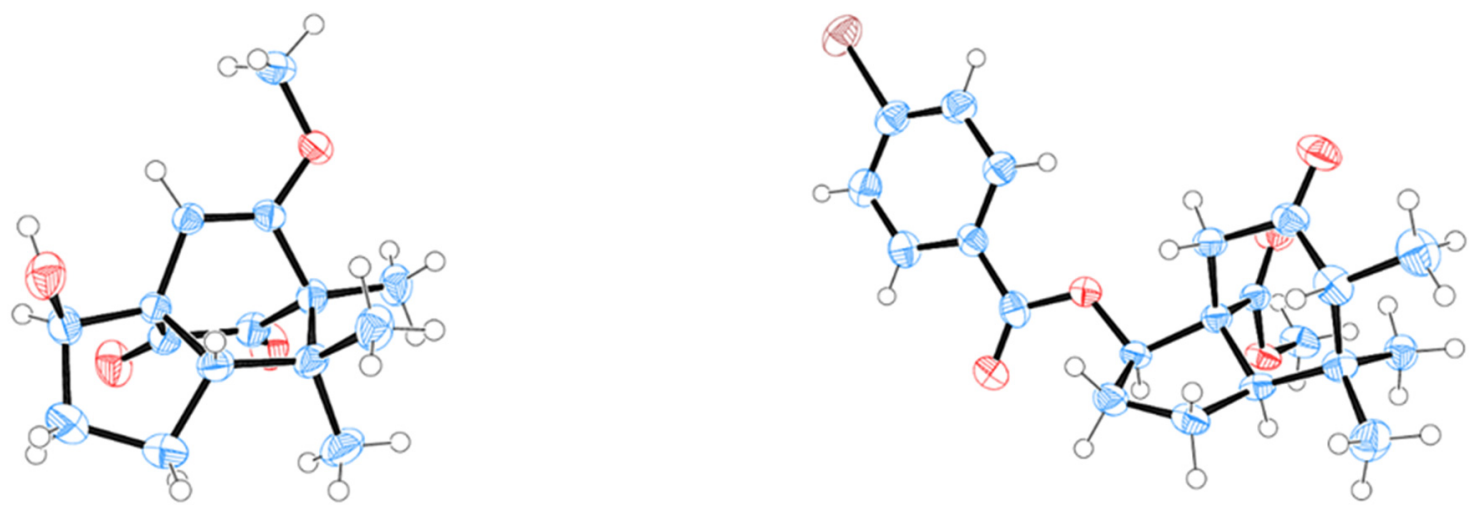

Figure 2. Ortep drawing of 20 and 22.

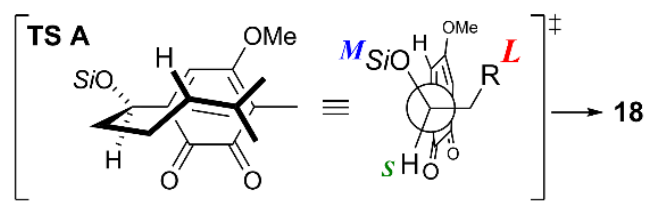

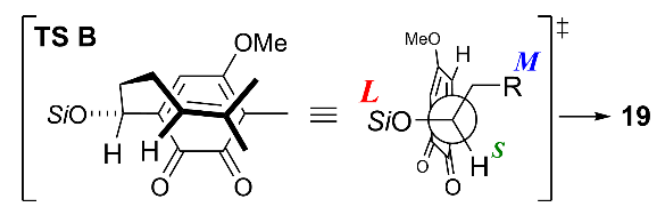

Figure 3. Plausible transition states of the IMDA reaction.

Next, we investigated the BAR using the major product 20 because of the pseudosymmetry of the bicyclo[2.2.2] octane skeleton (Scheme 4). The treatment of 20 with lithium hydroxide and subsequent esterification using trimethylsilyl diazomethane $\left(\mathrm{TMSCHN}_{2}\right)$ afforded $\alpha$-hydroxyester 25 in a $17 \%$ yield as a single product. After a thorough investigation, we found that the BAR of $\mathbf{2 0}$ did not provide the desired intermediate $\mathbf{2 4}$. However, triketone 23 was obtained by hydrolysis because of the $1 \mathrm{M}$ hydrochloric acid used for work-up. During the acid-base extraction to obtain a carboxylic acid, the skeletal rearrangement of triketone 23 by a retro-Claisen/aldol process proceeded under the basic conditions to produce $\alpha$-hydroxycarboxylic acid 24. Further, triketone 26, prepared by the hydrolysis of 18, was treated with $\mathrm{NaOH}$ aq. at room temperature and $\mathrm{TMSCHN}_{2}$ to afford $\alpha$-hydroxyester 27 in a $52 \%$ yield as a single product. The structure of 27 was determined using 2D NMR spectroscopy (see Supplementary Materials), except the stereochemistry at the $\mathrm{C} 8$ position. Further attempts for structure determination, such as recrystallization of 27 and its derivatives, were unsuccessful. Thus, our results support the fact that the retro-Claisen/aldol reaction can transform highly oxidized allo-cedranes to the skeleton of illisimonin $\mathrm{A}$ in biosynthesis as well as chemical synthesis. 


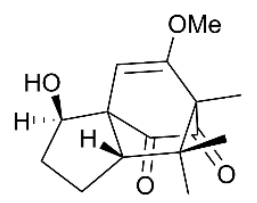

20

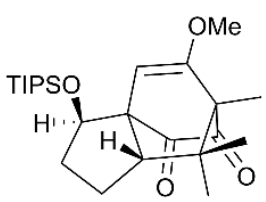

18

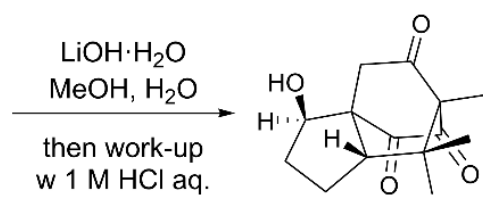

23

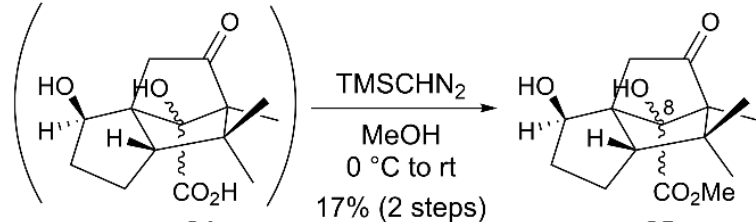

24
25

(single isomer)

ii) $1 \mathrm{M} \mathrm{HCl}$

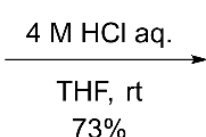

$73 \%$

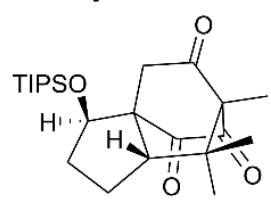

26

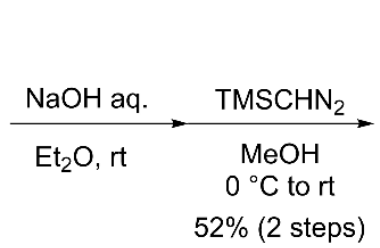

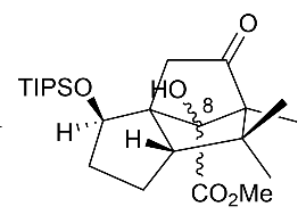

27

(single isomer)

Scheme 4. Attempts on the skeletal rearrangements of allo-cedranes.

\section{Conclusions}

In conclusion, we constructed the tricyclo[5.2.1. $\left.0^{1,5}\right]$ decane skeleton by an intramolecular Diels-Alder reaction using ortho-benzoquinones and a biomimetic skeletal rearrangement. We have achieved a concise synthesis of allo-cedranes (seven steps from commercially available 2,6-dimethoxytoluene) by the introduction of a prenyl side chain using the Grignard reaction, the oxidative dearomatization of 2-methoxyphenol, and the intramolecular Diels-Alder reaction of ortho-benzoquinone. Although the intramolecular Diels-Alder reaction proceeded with an undesired facial stereoselectivity, we obtained the desired cycloadduct as a minor product. Moreover, we have demonstrated that the skeletal rearrangement of allo-cedranes to the tricyclic skeleton of illisimonin A proceeds under basic conditions, not by a benzilic acid rearrangement but via a retro-Claisen/aldol reaction. Based on the results of the present study, further investigations into the total synthesis of illisimonin A are currently underway.

Supplementary Materials: The following are available online at https:/ /www.mdpi.com/article/10 $.3390 /$ org2030016/s1, PDF file containing X-ray crystallographic data for compound 20 and 22 and experimental procedures and copies of NMR Spectra (1H and 13C) for all new compounds.

Author Contributions: Conceptualization, T.S.; methodology, T.S.; investigation, R.N. and M.A.F.; data curation, M.A.F. and Y.Y.; writing —original draft preparation, T.S.; writing—review and editing, T.S., K.I. and K.T.; funding acquisition, T.S. All authors have read and agreed to the published version of the manuscript.

Funding: This research was funded by JSPS KAKENHI, grant number JP20K05485, JP21H01923 and JP21K14616. This work is also founded by the Photo-excitonix Project of Hokkaido University, the Kurata Memorial Hitachi Science and Technology Foundation and the Astellas Foundation for Research on Metabolic Disorders.

Institutional Review Board Statement: Not applicable.

Informed Consent Statement: Not applicable.

Data Availability Statement: Data are contained within supplementary material.

Conflicts of Interest: The authors declare no conflict of interest. 


\section{References}

1. Fukuyama, Y.; Huang, J.-M. Chemistry and Neurotrophic Activity of seco-Prezizaane- and Anislactone-type Sesquiterpenes from Illicium Species. In Studies in Natural Products Chemistry; Atta-ur-Rahman, Ed.; Elsevier: Amsterdam, The Netherlands, 2005; Volume 32, pp. 395-427.

2. Patra, J.K.; Das, G.; Bose, S.; Banerjee, S.; Vishnuprasad, C.N.; del Pilar Rodriguez-Torres, M.; Shin, H.-S. Star Anise (Illicium verum): Chemical Compounds, Antiviral Properties, and Clinical Relevance. Phytother. Res. 2020, 34, 1248-1267. [CrossRef]

3. Witkin, J.M.; Shenvi, R.A.; Li, X.; Gleason, S.D.; Weiss, J.; Morrow, D.; Catow, J.T.; Wakulchik, M.; Ohtawa, M.; Lu, H.-H.; et al. Pharmacological Characterization of the Neurotrophic Sesquiterpene Jiadifenolide Reveals a Non-Convulsant Signature and Potential for Progression in Neurodegenerative Disease Studies. Biochem. Pharmacol. 2018, 155, 61-70. [CrossRef] [PubMed]

4. Lane, J.F.; Koch, W.T.; Leeds, N.S.; Gorin, G. On the Toxin of Illicium Anisatum. I. The Isolation and Characterization of a Convulsant Principle: Anisatin. J. Am. Chem. Soc. 1952, 74, 3211-3215. [CrossRef]

5. Yamada, K.; Takada, S.; Nakamura, S.; Hirata, Y. The Structures of Anisatin and Neoanisatin: Toxic Sesquiterpenes from Illicium Anisatum L. Tetrahedron 1968, 24, 199-229. [CrossRef]

6. Fukuyama, Y.; Shida, N.; Kodama, M. Tashironin, a plausible biosynthetic precursor of anisatin-type sesquiterpenes. Tetrahedron Lett. 1995, 36, 583-586. [CrossRef]

7. Huang, J.-M.; Yokoyama, R.; Yang, C.-S.; Fukuyama, Y. Merrilactone A, a Novel Neurotrophic Sesquiterpene Dilactone from Illicium merrillianum. Tetrahedron Lett. 2000, 41, 6111-6114. [CrossRef]

8. Huang, J.-M.; Yokoyama, R.; Yang, C.-S.; Fukuyama, Y. Structure and Neurotrophic Activity of seco-Prezizaane-Type Sesquiterpenes from Illicium merrillianum. J. Nat. Prod. 2001, 64, 428-431. [CrossRef] [PubMed]

9. Kubo, M.; Okada, C.; Huang, J.-M.; Harada, K.; Hioki, H.; Fukuyama, Y. Novel Pentacyclic seco-Prezizaane-Type Sesquiterpenoids with Neurotrophic Properties from Illicium jiadifengpi. Org. Lett. 2009, 11, 5190-5193. [CrossRef] [PubMed]

10. Urabe, D.; Inoue, M. Total Syntheses of Sesquiterpenes from Illicium Species. Tetrahedron 2009, 65, 6271-6289. [CrossRef]

11. Condakes, M.L.; Novaes, L.F.T.; Maimone, T.J. Contemporary Synthetic Strategies toward Seco-Prezizaane Sesquiterpenes from Illicium Species. J. Org. Chem. 2018, 83, 14843-14852. [CrossRef]

12. Ogura, A.; Yamada, K.; Yokoshima, S.; Fukuyama, T. Total Synthesis of (-)-Anisatin. Org. Lett. 2012, 14, 1632-1635. [CrossRef]

13. Xu, J.; Trzoss, L.; Chang, W.K.; Theodorakis, E.A. Enantioselective Total Synthesis of (-)-Jiadifenolide. Angew. Chem. Int. Ed. 2011, 50, 3672-3676. [CrossRef] [PubMed]

14. Siler, D.A.; Mighion, J.D.; Sorensen, E.J. An Enantiospecific Synthesis of Jiadifenolide. Angew. Chem. Int. Ed. 2014, 53, 5332-5335. [CrossRef] [PubMed]

15. Paterson, I.; Xuan, M.; Dalby, S.M. Total Synthesis of Jiadifenolide. Angew. Chem. Int. Ed. 2014, 53, 7286-7289. [CrossRef]

16. Lu, H.H.; Martinez, M.D.; Shenvi, R.A. An eight-step gram-scale synthesis of (-)-jiadifenolide. Nat. Chem. 2015, 7, 604-607. [CrossRef] [PubMed]

17. Shen, Y.; Li, L.; Pan, Z.; Wang, Y.; Li, J.; Wang, K.; Wang, X.; Zhang, Y.; Hu, T.; Zhang, Y. Protecting-Group-Free Total Synthesis of (-)-Jiadifenolide: Development of a [4 + 1] Annulation toward Multisubstituted Tetrahydrofurans. Org. Lett. 2015, 17, 5480-5483. [CrossRef]

18. Gomes, J.; Daeppen, C.; Liffert, R.; Roesslein, J.; Kaufmann, E.; Heikinheimo, A.; Neuburger, M.; Gademann, K. Formal Total Synthesis of (-)-Jiadifenolide and Synthetic Studies toward seco-Prezizaane-Type Sesquiterpenes. J. Org. Chem. 2016, 81, 11017-11034. [CrossRef]

19. Mehta, G.; Maity, P. A Total Synthesis of 11-O-Methyldebenzoyltashironin. Tetrahedron Lett. 2011, 52, 1749-1752. [CrossRef]

20. Ohtawa, M.; Krambis, M.J.; Cerne, R.; Schkeryantz, J.M.; Witkin, J.M.; Shenvi, R.A. Synthesis of (-)-11-O-Debenzoyltashironin: Neurotrophic Sesquiterpenes Cause Hyperexcitation. J. Am. Chem. Soc. 2017, 139, 9637-9644. [CrossRef] [PubMed]

21. Chen, J.; Gao, P.; Yu, F.; Yang, Y.; Zhu, S.; Zhai, H. Total Synthesis of (土)-Merrilactone A. Angew. Chem. Int. Ed. 2012, 51, 5897-5899. [CrossRef]

22. Liu, W.; Wang, B. Synthesis of ( \pm )-Merrilactone A by a Desymmetrization Strategy. Chem.-Eur. J. 2018, 24, 16511-16515. [CrossRef] [PubMed]

23. Shen, Y.; Li, L.; Xiao, X.; Yang, S.; Hua, Y.; Wang, Y.; Zhang, Y.; Zhang, Y. Site-Specific Photochemical Desaturation Enables Divergent Syntheses of Illicium Sesquiterpenes. J. Am. Chem. Soc. 2021, 143, 3256-3263. [CrossRef]

24. Ma, S.-G.; Li, M.; Lin, M.-B.; Li, L.; Liu, Y.-B.; Qu, J.; Li, Y.; Wang, X.-J.; Wang, R.-B.; Xu, S.; et al. Illisimonin A, a Caged Sesquiterpenoid with a Tricyclo[5.2.1.0 ${ }^{1,6}$ ]decane Skeleton from the Fruits of Illicium simonsii. Org. Lett. 2017, 19, 6160-6163. [CrossRef]

25. Burns, A.S.; Rychnovsky, S.D. Total Synthesis and Structure Revision of (-)-Illisimonin A, a Neuroprotective Sesquiterpenoid from the Fruits of Illicium simonsii. J. Am. Chem. Soc. 2019, 141, 13295-13300. [CrossRef]

26. Gill, G.B. Benzil-Benzilic acid Rearrangements. In Comprehensive Organic Synthesis; Trost, B.M., Fleming, I., Eds.; Elsevier: Amsterdam, The Netherlands, 1991; Volume 3, pp. 821-838.

27. Deb, S.; Chakraborti, R.; Ghatak, U.R. Synthesis of 1-p-Methoxyphenyl and 1-p-Methoxyphenyl-4-methylbicyclo[2.2.1]heptan-7one. The Oxidation of 7-Hydroxy-1-p-methoxyphenyl-4-methylbicyclo[2.2.1]heptan-7-carboxylic Acid with Lead Tetraacetate. Synth. Comm. 1993, 23, 913-924. [CrossRef]

28. Song, L.; Zhu, G.; Liu, Y.; Liu, B.; Qin, S. Total Synthesis of Atisane-Type Diterpenoids: Application of Diels-Alder Cycloadditions of Podocarpane-Type Unmasked ortho-Benzoquinones. J. Am. Chem. Soc. 2015, 137, 13706-13714. [CrossRef] 
29. Nicolaou, K.C.; Wang, J.; Tang, Y.; Botta, L. Total Synthesis of Sporolide B and 9-epi-Sporolide B. J. Am. Chem. Soc. 2010, 132, 11350-11363. [CrossRef] [PubMed]

30. Gu, Q.-S.; Yang, D. Enantioselective Synthesis of (+)-Mitomycin K by a Palladium-Catalyzed Oxidative Tandem Cyclization. Angew. Chem. Int. Ed. 2017, 56, 5886-5889. [CrossRef] [PubMed]

31. Kitahara, Y.; Nakahara, S.; Numata, R.; Kubo, A. Synthesis of 4,7-Indolequinones. The Oxidative Demethylation of 4,7Dimethoxyindoles with Ceric Ammonium Nitrate. Chem. Pharm. Bull. 1985, 33, 2122-2128. [CrossRef]

32. Magauer, T.; Martin, H.J.; Mulzer, J. Ring-Closing Metathesis and Photo-Fries Reaction for the Construction of the Ansamycin Antibiotic Kendomycin: Development of a Protecting Group Free Oxidative Endgame. Chem. Eur. J. 2010, 16, 507-519. [CrossRef] 